\title{
DPPF-Mediated C-H Arylation of Arenes with Aryl lodides for Synthesis of Biaryl Linkages
}

WANG Qingbing, GUO Zhengwei, CHEN Gong ${ }^{*}$, HE Gang *

State Key Laboratory and Institute of Elemento-Organic Chemistry, College of Chemistry, Nankai University, Tianjin 300071, P. R. China.

Abstract: The broad existence of the biaryl linkage in bioactive organic molecules and functional materials makes it an attractive synthesis target via construction of aryl-aryl carbon bonds. Transition metal catalyzed cross-coupling reactions of two pre-functionalized aryl partners, e.g., SuzukiMiyaura cross-coupling and Negishi cross-coupling
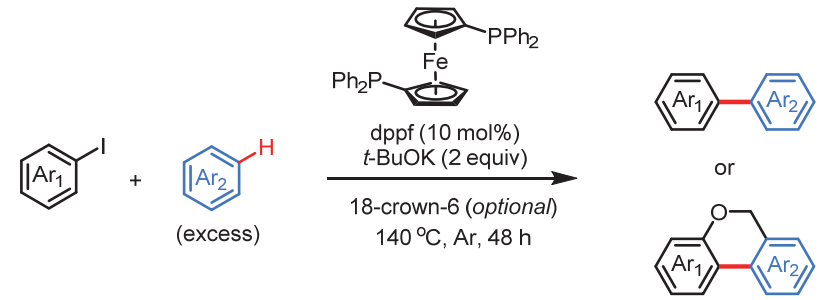
reactions, are the main methods typically used for the construction of biaryl linkages. Since the end of the last century, transition metal catalyzed direct $\mathrm{C}-\mathrm{H}$ arylation of unactivated arenes has emerged as a practical alternative to the well-established cross-coupling strategies. However, the use of transition metal catalysts and/or organometallic reagents would lead to problems, such as the disposal of waste from large-scale syntheses and the removal of heavy metal contaminants from pharmaceutical intermediates. In this regard, the base-promoted homolytic aromatic substitution (BHAS) reaction of aryl halides with unactivated arenes offers a simpler strategy for the synthesis of biaryl scaffolds, and avoids the use of transition metals. Although the BHAS reaction can proceed to a small extent without any additives, particularly at elevated temperatures, the addition of organic promoters would significantly accelerate the reaction rate and improve the overall efficiency of the process. Over the past ten years, a wide variety of $\mathrm{N}$ - and O-based organic promoters have been developed to promote the BHAS reaction in the presence of the tert-butoxide base. The mechanism of the BHAS reaction has been studied extensively, and is accepted as occurring via a radical chain process involving an aryl radical. However, the role and mode of initiation of most organic promoters studied remain controversial. The development of more and varied organic promoters will surely promote the mechanistic understanding and further development of the BHAS reaction. Herein, we report that 1,1'-bis(diphenylphosphino)ferrocene (dppf, or DPPF) can act as a P-based promoter to facilitate the direct arylation of unactivated arenes with aryl iodides using potassium tert-butoxide as the base and electron donor. A broad range of aryl iodides and arenes reacted smoothly under the optimized reaction conditions, giving arylated products in good yields and with high regio-selectivity. Intramolecular $\mathrm{C}-\mathrm{H}$ arylation also worked well following a sequence of single electron transfer (SET)/initiation, 5-exo-trig aryl radical addition, ring expansion, deprotonation, and re-aromatization/propagation. A mechanistic study indicated that the diphenylphosphino group of dppf played a vital role in the initiation step by enhancing the SET-inhibiting ability of the tert-butoxide anion. A primary kinetic isotope effect was observed in the parallel reactions between 4-methoxy-iodobenzene with benzene and deuterated benzene, implying that the deprotonation of the cyclohexadienyl radical intermediate by tert-butoxide was the ratedetermining step in the radical chain pathway.

Key Words: $\mathrm{C}-\mathrm{H}$ arylation; tert-butoxide; DPPF; Radical; Biaryl synthesis

Received: November 30, 2018; Revised: January 12, 2019; Accepted: January 22, 2019; Published online: January 24, 2019.

* Corresponding authors. Emails: gongchen@nankai.edu.cn (C.G.); hegang@nankai.edu.cn (H.G.). Tel.: +86-18622363249 (H.G.).

The project was supported by the National Natural Science Foundation of China $(21672105,21725204,91753124)$ and Natural Science Foundation of Tianjin, China (17JCYBJC19700, 18JCZDJC32800).

国家自然科学基金(21672105, 21725204, 91753124)与天津市自然科学基金(17JCYBJC19700, 18JCZDJC32800)资助项目

(C) Editorial office of Acta Physico-Chimica Sinica 


\title{
1,1'-双 (二苯基膦基)二茂铁介导的芳烃碳氢键芳基化反应制备联芳基 骨架
}

\author{
王庆兵，郭政伟，陈弓*，何刚* \\ 南开大学化学学院元素有机国家重点实验室, 天津 300071
}

\begin{abstract}
摘要：联芳基骨架的合成过去主要依赖于过渡金属催化的交叉偶联反应和碳氢键芳基化反应。近年来，碱促进的芳基卤 化物与非活化芳烃的自由基芳香取代反应(BHAS)得到了广泛的关注，为合成联芳基骨架提供了更简洁的策略。在本文 中, 我们报道了使用叔丁醇钾作碱和电子供体, $\operatorname{dppf}\left(1,1^{\prime}\right.$-双 (二苯基膦基)二茂铁)介导的非活化芳烃与芳基碘的直接芳基 化反应。在标准反应条件下，一系列具有不同取代基团的芳基碘化物和芳烃都能顺利反应，以良好的收率和区域选择性 生成芳基化产物。分子内芳基化反应也可以顺利进行：该反应经历了单电子转移(SET)/引发、5-exo-trig自由基加成、扩 环、去质子化和芳构化/链增长等步骤。机理研究表明, dppf骨架中的二茶基膦基团通过与叔丁醇阴离子作用提高其单电 子还原能力，是顺利引发反应的关键。同时，同位素效应实验结果表明叔丁醇钾与环己二烯基自由基中间体的去质子化 过程是整个反应中的决速步。
\end{abstract}

关键词：碳氢键芳基化; 叔丁醇钾; 1,1'-双(二苯基膦)二茂铁; 自由基; 联芳基合成 中图分类号: 0643

\section{Introduction}

Biaryl linkages are important structural motif that are widely found in natural products, pharmaceuticals and functional molecules ${ }^{1}$. Direct arylation of unactivated arenes is one of the most straightforward method to construct biaryl scaffolds. In this regard, transition metal catalyzed direct $\mathrm{C}\left(s p^{2}\right)-\mathrm{H}$ arylation reactions of arenes have made great progress over the past twenty years ${ }^{2-4}$. Alternatively, homolytic aromatic substitution reaction (HAS) offers a complementary strategy to make biaryl scaffolds via radical addition without the use of transition metals ${ }^{5,6}$. In 2008, Itami reported a $t$-BuOK promoted arylation of haloarenes with N-heterocycles ${ }^{7}$. Soon afterward, Lei and Kwong, Shi, and Hayashi independently developed $t$-BuOK or $t$-BuONa promoted arylation of unactivated arenes with haloarenes in the presence of various organic promoters (Scheme 1A) ${ }^{8-10}$. The reaction was recognized as a base prompted homolytic aromatic substitution reaction (BHAS), following the sequence of single electron transfer (SET)/initiation, aryl radical addition, deprotonation and rearomatization/propagation 11,12. Since then, many $\mathrm{N}$ and $\mathrm{O}$ based organic promoters were reported to facilitate this BHAS reaction ${ }^{13-35}$. Recently, our group developed a 1,1'-bis(diphenylphosphino)ferrocene (dppf or DPPF) mediated $\mathrm{C}-\mathrm{H}$ arylation of oxazoles with $\mathrm{Cs}_{2} \mathrm{CO}_{3}$ or $t$-BuOK as the base and electron donor ${ }^{36}$. The interaction of dppf ${ }^{37}$ with $\mathrm{Cs}_{2} \mathrm{CO}_{3}$ or $t$-BuOK enhanced their SET reducing ability to generate aryl radical from aryl iodide (Scheme 1B). Herein, we expand this strategy to the arylation of unactivated arenes with aryl iodide using dppf and $t$-BuOK base (Scheme $1 C)$.

\section{Experimental and computational section}

2.1 Materials and reagents

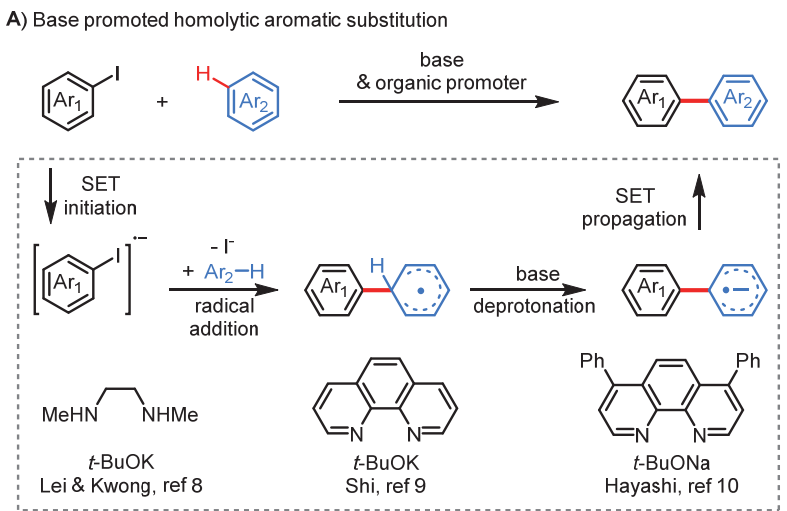

B) Our previous work: dppf mediated C-H arylation of oxazoles

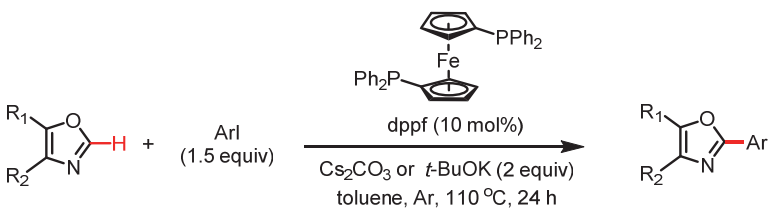

C) This work: dppf mediated $\mathrm{C}-\mathrm{H}$ arylation of arenes

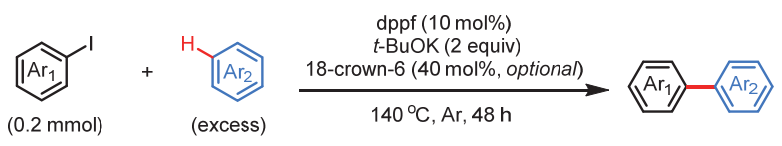

Scheme 1 Base promoted homolytic aromatic substitution of arenes.

All commercial materials were used as received unless otherwise noted. TLC were performed on silica gel Huanghai HSGF254 plates and visualization of the developed chromatogram was performed by fluorescence quenching $\left(\lambda_{\max }=\right.$ $254 \mathrm{~nm}$ ). Flash chromatography was performed using Silica gel (200-300 mesh) purchased from Qingdao Haiyang Chemical Co., China. dppf (98\%, J\&K Chemical, China), $t$-BuOK (99\%, $\mathrm{J} \& \mathrm{~K}$ Chemical, China) were used in the $\mathrm{C}-\mathrm{H}$ Arylation reaction. 


\subsection{Instruments and methods}

LC-MS was performed on a Thermo Scientific MSQ instrument with the spectrometer operating in positive mode. NMR spectra were recorded on Bruker AVANCE AV 400 instruments, using residual solvent peaks (chloroform $(\delta=7.26)$ for ${ }^{1} \mathrm{H}$ NMR, chloroform $(\delta=77.16)$ for $\left.{ }^{13} \mathrm{C} \mathrm{NMR}\right)$ as internal reference. High resolution ESI mass experiments were operated on a Thermo Fisher Q Exactive Focus of instrument.

\subsection{General procedure for the arylation of arene with aryl-iodide}

Aryl iodide (0.2 mmol, 1 equiv), dppf (11.1 mg, $0.02 \mathrm{mmol}$, $10 \%$ (molar fraction)), $t$-BuOK ( $45 \mathrm{mg}, 0.4 \mathrm{mmol}, 2$ equiv) and $1.5 \mathrm{~mL}$ arene were added to a $8 \mathrm{~mL}$ glass vial at room temperature in glove box. The vial was sealed with polytetrafluoroethylene (PTFE) cap and move out of glove box. The reaction mixture was heated at $140{ }^{\circ} \mathrm{C}$ for $48 \mathrm{~h}$ under Ar atmosphere. After being cooled to room temperature, the reaction mixture was diluted with dichloromethane (DCM) (6 $\mathrm{mL}$ ). The resulting mixture was allowed to stir for $10 \mathrm{~min}$ and then filtered through a pad of celite. The filtrate was concentrated in vacuo, the resulting residue was subjected to ${ }^{1} \mathrm{H}$ NMR analysis using 1,1,2,2-tetrachloroethane as internal standard or purified by silica gel flash chromatography to give the desired product.

\section{Results and discussion}

\subsection{Optimization of reaction conditions}

As shown in Table 1, the model reaction of 4-methoxy-

Table 1 Optimization of $\mathrm{C}-\mathrm{H}$ arylation of benzene ${ }^{\mathrm{a}}$.
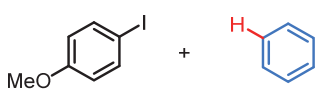

dppf (10 mol\%)

base (2 equiv)

$\mathrm{Ar}, 48 \mathrm{~h}$

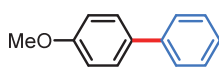

$(1.5 \mathrm{~mL})$

\begin{tabular}{|c|c|c|}
\hline Entry & Condition & Yield $(\%)^{b}$ \\
\hline 1 & $\mathrm{Cs}_{2} \mathrm{CO}_{3}$ (2 equiv), $110^{\circ} \mathrm{C}$ & $<10$ \\
\hline 2 & $t$ - $\mathrm{BuOK}$ ( 2 equiv), $110^{\circ} \mathrm{C}$ & 64 \\
\hline 3 & $t$ - $\mathrm{BuONa}$ ( 2 equiv), $110^{\circ} \mathrm{C}$ & NR \\
\hline 4 & $t-\operatorname{BuOLi}(2$ equiv $), 110^{\circ} \mathrm{C}$ & NR \\
\hline 5 & $t$-BuOK ( 2 equiv), $130^{\circ} \mathrm{C}$ & 73 \\
\hline 6 & $t$-BuOK ( 2 equiv), $140^{\circ} \mathrm{C}$ & $78(73)^{\mathrm{c}}$ \\
\hline 7 & $t$ - BuOK ( 2 equiv), TBAI ( 0.2 equiv), $130^{\circ} \mathrm{C}$ & 28 \\
\hline 8 & $t$ - $\mathrm{BuOK}$ ( 2 equiv), $\mathrm{TBAB}\left(0.2\right.$ equiv), $130^{\circ} \mathrm{C}$ & 30 \\
\hline 9 & $\operatorname{dppf}(20 \%(x)), t-\mathrm{BuOK}$ (2 equiv), $130^{\circ} \mathrm{C}$ & 74 \\
\hline 10 & $t$-BuOK (2 equiv), 18 -crown-6 $(40 \%(x)), 140{ }^{\circ} \mathrm{C}$ & 61 \\
\hline 11 & $t$-BuOK (2 equiv), 18 -crown-6 $(40 \%(x)), 140^{\circ} \mathrm{C}$ & $51^{\mathrm{d}}$ \\
\hline 12 & $t$-BuOK ( 2 equiv), $140^{\circ} \mathrm{C}$ & $25^{\mathrm{d}}$ \\
\hline
\end{tabular}

a All screening reactions were carried out on a $0.2 \mathrm{mmol}$ scale at $0.13 \mathrm{~mol} \cdot \mathrm{L}^{-1}$ concentration. ${ }^{b}$ Yields are based on ${ }^{1} \mathrm{H}$ NMR analysis of the crude reaction solution using 1,1,2,2-tetrachloroethane as internal standard; ${ }^{\mathrm{c}}$ Isolated yield; ${ }^{\mathrm{d}}$ without dppf. NR: no reaction, most of the starting material recovered. TBAB: tetrabutylammonium bromide. TBAI: tetrabutylammonium iodide. $x$ : molar fraction. iodobenzene 1 with benzene gave trace amount of the desired product 3 under our previous reaction conditions $\left(\mathrm{Cs}_{2} \mathrm{CO}_{3}\right.$ as base at $110{ }^{\circ} \mathrm{C}$, entry 1$)$. When $\mathrm{Cs}_{2} \mathrm{CO}_{3}$ was replaced by $t$-BuOK, the yield was improved significantly, affording compound $\mathbf{3}$ in 64\% NMR yield along with some unreacted starting material 1 ( $\sim 30 \%$, entry 2). In contrast, $t$-BuONa and $t$-BuOLi were unable to promote the arylation reaction (entries 3 and 4). Complete conversation were achieved at elevated temperature, giving compound 3 in 73\% isolated yield (entry 6). Addition of other electron donor reagents all caused decreased yield (entries 7 and 8) ${ }^{38}$. Addition of $40 \%$ (molar fraction) of 18 -crown- 6 also gave slightly diminished yield (entry 10). And the reaction without dppf gave the arylated compound $\mathbf{3}$ in low yield.

\subsection{Intermolecular arylation of arenes with aryl-iodides}

With the optimized reaction conditions in hand (conditions $\mathbf{A}$, Table 1, entry 6), we evaluated the substrate of aryl-iodides with benzene (Scheme 2A). As shown in $\mathbf{3 - 8}$, aryl-iodides bearing either electron-donating or withdrawing groups gave good yields of product. Coupling of sterically more hindered orthosubstituted aryl iodide (see 5) also worked well. Notably, no regioisomers were observed under the standard reaction conditions, thus the benzyne intermediate was unambiguously ruled out. Coupling of 4-phenyl-iodobenzene with benzene afforded compound $\mathbf{1 1}$ in $\mathbf{7 2} \%$ yield. Alternatively, compound $\mathbf{1 1}$ was obtained with comparable yield from 4-chloro-iodobenzene with benzene via double arylation reaction (Scheme 2B). In contrast, aryl chloride without an iodo group failed to give any arylation product.

Arylation with other unactivated arenes were investigated with 4-methoxy-iodobenzene 1 (Scheme 2C). As seen in compound 12, arylation of toluene under conditions $\mathbf{A}$ gave the desired product with low conversion; gratifyingly, addition of $40 \%$ (molar fraction) of 18-crown- 6 afforded much improved yield (conditions B, Table 1, entry 10). Good ortho regioselectivity were observed $(\mathbf{1 2}, \mathbf{1 3})$, which is consistent with the radical addition mechanism of BHAS reaction ${ }^{39}$. Fluoro substituted arenes were compatible with the arylation reaction, affording the arylated products with good yields and regioselectivity $(\mathbf{1 4}, \mathbf{1 5})$. The arylation of 1,3-dimethoxy-benzene gave compound $\mathbf{1 7}$ in moderate yield, with the preference of ortho position.

\subsection{Intramolecular arylation of arenes with aryl-iodides}

As shown in Scheme 3, intramolecular arylation reaction also worked well under slightly modified conditions $(20 \%$ (molar fraction) of dppf, $40 \%$ (molar fraction) of 18 -crown-6, and 2 equiv of $t$-BuOK in mesitylene at $120{ }^{\circ} \mathrm{C}$, conditions C) ${ }^{40-44}$. Arylation of unsubstituted phenyl $\left(\mathrm{Ar}_{2}\right)$ with aryl-iodide $\left(\mathrm{Ar}_{1}\right)$ yielded the cyclized product in moderate to good yields (18-20). When substrates with para-methoxy substituted phenyl (21) and meta-substituted phenyl (23) were applied to the cyclization conditions, compound $\mathbf{2 2}$ and $\mathbf{2 4}$ were obtained in moderate 


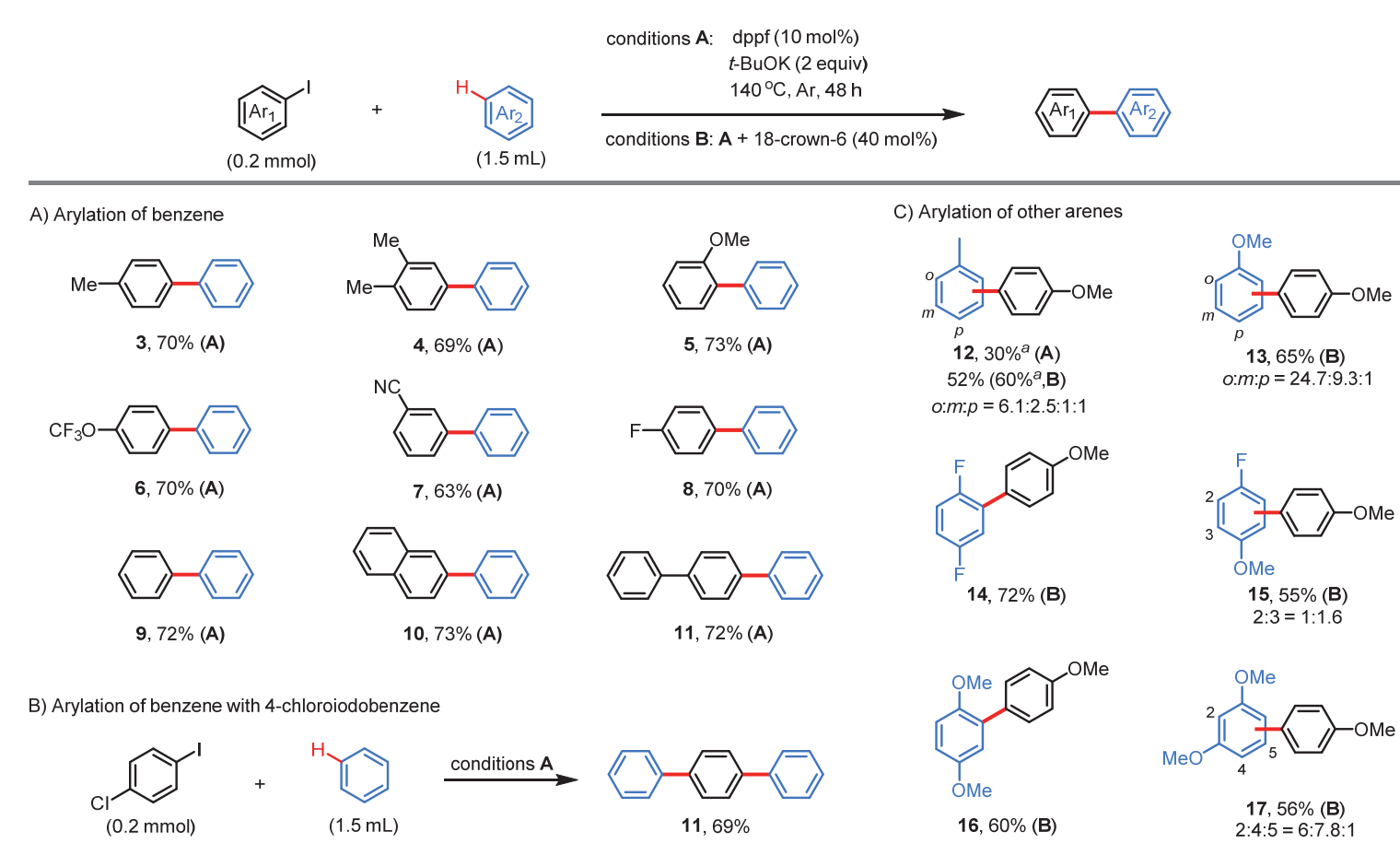

Scheme 2 DPPF mediated intermolecular $\mathbf{C}-\mathrm{H}$ arylation of arenes.

Isolated yield on a $0.2 \mathrm{mmol}$ scale. ${ }^{\text {a }} \mathrm{GC}-\mathrm{MS}$ yield.

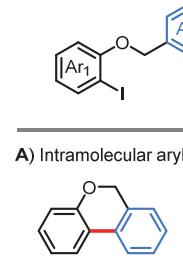

$18,50 \%$

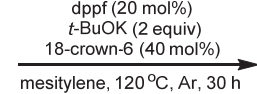
(conditions $\mathrm{C}$ )

stituted phenyl

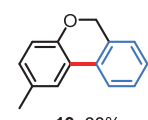

$19,68 \%$

B) Intramolecular arylation at substituted phenyl

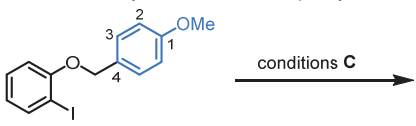

21

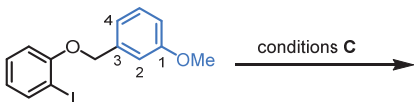

23

C) Proposed mechanism

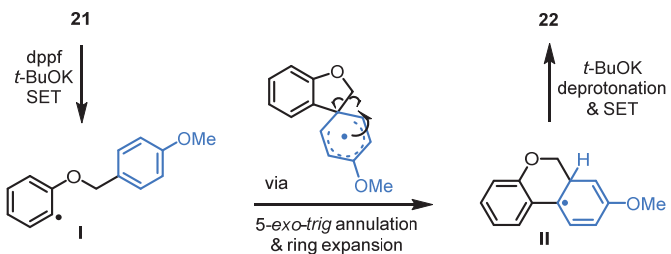

Scheme 3 DPPF mediated intramolecular $\mathrm{C}-\mathrm{H}$ arylation of arenes.

Isolated yield on a $0.2 \mathrm{mmol}$ scale.

yields (Scheme 3B). Formation of the migrated cyclization product was triggered by single electron transfer from the complex of dppf and $t$-BuOK to generate aryl radical I. After intramolecularly favored 5-exo-trig annulation, the resulting spirocyclohexadienyl radical underwent a concerted ring expansion to give radical intermediate II. Radical intermediate
A) Comparasion of different ferrocene based catalyst.

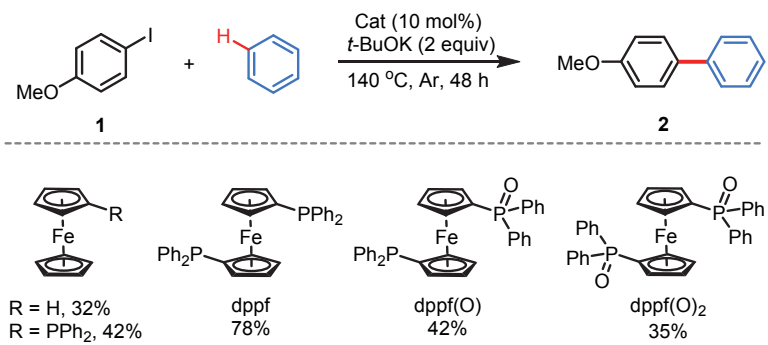

B) KIE study

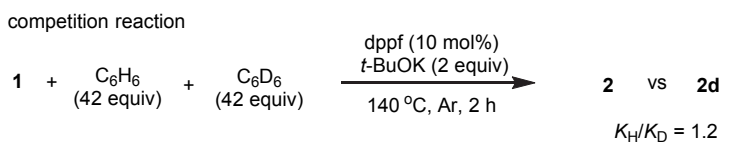

paprallel reactions

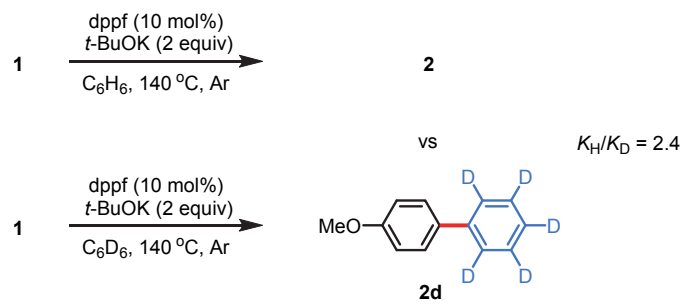

Scheme 4 Control experiments and KIE study.

$$
{ }^{a} \text { NMR yield. }
$$

II was deprotonated by $t$-BuOK to generate a radical anion, which was transformed to the final product 22 via SET with 21 and regenerate radical $\mathbf{I}$ thus continuing the radical chain reaction.

\subsection{Control experiments and KIE study}

Some control reactions were conducted to probe the 
mechanism. As shown in Scheme 4A, the catalytic ability of several dppf analogues were tested with the arylation of benzene with aryl iodide 1. All the dppf analogues tested afforded diminished yields, which was consistent with our previous result that the SET reducing ability of $t-\mathrm{BuO}^{-}$was enhanced via complexation with the diphenylphosphino group of $\mathrm{dppf}^{36}$. 18crown- 6 may assists the solvation of $t$-BuOK, increasing the concentration of $t-\mathrm{BuO}^{-}$, thus making the whole process more feasible. A low KIE value (1.2) was observed in the competition reaction between benzene and deuterated benzene. However, a primary isotope effect $\left(K_{\mathrm{H}} / K_{\mathrm{D}}=2.4\right)$ was obtained from the parallel reactions (Scheme $4 \mathrm{~B}$ ), implying that the $\mathrm{C}-\mathrm{H}$ bond cleavage is the rate-determining step ${ }^{45}$.

\section{Conclusions}

We developed a BHAS reaction of unactivated arenes with aryl iodide using dppf promoter and $t$-BuOK as the base and electron donor. Both intermolecular and intramolecular $\mathrm{C}-\mathrm{H}$ aryaltion of arenes gave moderate to good yields with good regio-slectivity. KIE studies indicated that the deprotonation step in the radical chain is the rate-determining step.

Supporting Information: available free of charge via the internet at http://www.whxb.pku.edu.cn.

\section{References}

(1) Bringmann, G.; Walter, R.; Weirich, R. Angew. Chem. Int. Edit. 1990, 29, 977. doi: 10.1002/anie.199009771

(2) Zhang, Y. -F.; Shi, Z. -J. Acc. Chem. Res. 2018, 52, 161. doi: 10.1021/acs.accounts. 8 b00408

(3) Lei, A.; Liu, W.; Liu, C.; Chen, M. Dalton Trans. 2010, 39, 10352. doi: $10.1039 / \mathrm{c} 0 \mathrm{dt} 00486 \mathrm{c}$

(4) Ackermann, L.; Vicente, R.; Kapdi, A. R. Angew. Chem. Int. Edit. 2009, 48, 9792. doi: 10.1002/anie.200902996

(5) Bolton, R.; Williams, G. H. Chem. Soc. Rev. 1986, 15, 261. doi: $10.1039 / \operatorname{cs} 9861500261$

(6) Bowman, W. R.; Storey, J. M. Chem. Soc. Rev. 2007, 36, 1803. doi: $10.1039 / \mathrm{b} 605183 \mathrm{a}$

(7) Yanagisawa, S.; Ueda, K.; Taniguchi, T.; Itami, K. Org. Lett. 2008, 10, 4673. doi: 10.1021/o18019764

(8) Liu, W.; Cao, H.; Zhang, H.; Zhang, H.; Chung, K. H.; He, C.; Wang, H.; Kwong, F. Y.; Lei, A. J. Am. Chem. Soc. 2010, 132, 16737. doi: $10.1021 / \mathrm{ja} 103050 \mathrm{x}$

(9) Sun, C. -L.; Li, H.; Yu, D. -G.; Yu, M.; Zhou, X.; Lu, X. -Y.; Huang, K.; Zheng, S. -F.; Li, B. -J.; Shi, Z. -J. Nat. Chem. 2010, $2,1044$. doi: 10.1038/NCHEM.862

(10) Shirakawa, E.; Itoh, K. -I.; Higashino, T.; Hayashi, T. J. Am. Chem. Soc. 2010, 132, 15537. doi: 10.1021/ja1080822

(11) Leadbeater, N. E. Nat. Chem. 2010, 2, 1007. doi: 10.1038/ NCHEM.913

(12) Studer, A.; Curran, D. P. Angew. Chem. Int. Edit. 2011, 50, 5018. doi: 10.1002/anie.201101597

(13) Pan, S. C. Beilstein J. Org. Chem. 2012, 8, 1374. doi: $10.3762 /$ bjoc. 8.159

(14) Chan, T. L.; Wu, Y.; Choy, P. Y.; Kwong, F. Y. Chem. -Eur. J. 2013, 19, 15802. doi: 10.1002/chem.201301583

(15) Sun, C. -L.; Shi, Z. -J. Chem. Rev. 2014, 114, 9219. doi: $10.1021 / \mathrm{cr} 400274 \mathrm{j}$

(16) Hofmann, J.; Heinrich, M. R. Tetrahedron Lett. 2016, 57, 4334 doi: 10.1016/j.tetlet.2016.08.034

(17) Qiu, Y.; Liu, Y.; Yang, K.; Hong, W.; Li, Z.; Wang, Z.; Yao, Z.; Jiang, S. Org. Lett. 2011, 13, 3556. doi: 10.1021/o12009208

(18) Liu, H.; Yin, B.; Gao, Z.; Li, Y.; Jiang, H. Chem. Commun. 2012, 48, 2033. doi: $10.1039 / \mathrm{c} 2 \mathrm{cc} 16790 \mathrm{e}$

(19) Ng, Y. S.; Chan, C. S.; Chan, K. S. Tetrahedron Lett. 2012, 53, 3911. doi: 10.1016/j.tetlet.2012.05.073

(20) Tanimoro, K.; Ueno, M.; Takeda, K.; Kirihata, M.; Tanimori, S. J. Org. Chem. 2012, 77, 7844. doi: 10.1021/jo3008594

(21) Chen, W. -C.; Hsu, Y. -C.; Shih, W. -C.; Lee, C. -Y.; Chuang, W. -H.; Tsai, Y. -F.; Chen, P. P. -Y.; Ong, T. -G. Chem. Commun. 2012, 48, 6702. doi: $10.1039 / \mathrm{c} 2 \mathrm{cc} 32519 \mathrm{e}$

(22) Sharma, S.; Kumar, M.; Kumar, V.; Kumar, N. Tetrahedron Lett. 2013, 54, 4868. doi: 10.1016/j.tetlet.2013.06.125

(23) Liu, W.; Tian, F.; Wang, X.; Yu, H.; Bi, Y. Chem. Commun. 2013, 49, 2983. doi: $10.1039 / \mathrm{c} 3 \mathrm{cc} 40695 \mathrm{~d}$

(24) Zhao, H.; Shen, J.; Guo, J.; Ye, R.; Zeng, H. Chem. Commun. 2013, 49, 2323. doi: $10.1039 / \mathrm{c} 3 \mathrm{cc} 00019 \mathrm{~b}$

(25) Song, Q.; Zhang, D.; Zhu, Q.; Xu, Y. Org. Lett. 2014, 16, 5272. doi: $10.1021 / 01502370 \mathrm{r}$

(26) Cuthbertson, J.; Gray, V. J.; Wilden, J. D. Chem. Commun. 2014, 50, 2575. doi: $10.1039 / \mathrm{c} 3 \mathrm{cc} 49019 \mathrm{j}$

(27) Wu, Y.; Choy, P. Y.; Kwong, F. Y. Org. Biomol. Chem. 2014, 12, 6820. doi: 10.1039/c4ob01211a

(28) Yi, H.; Jutand, A.; Lei, A. Chem. Commun. 2015, 51, 545. doi: $10.1039 / \mathrm{c} 4 \mathrm{cc} 07299 \mathrm{e}$

(29) Zhou, S.; Anderson, G. M.; Mondal, B.; Doni, E.; Ironmonger, V.; Kranz, M.; Tuttle, T.; Murphy, J. A. Chem. Sci. 2014, 5, 476. doi: $10.1039 / \mathrm{c} 3 \mathrm{sc} 52315 \mathrm{~b}$

(30) Zhou, S.; Doni, E.; Anderson, G. M.; Kane, R. G.; MacDougall, S. W.; Ironmonger, V. M.; Tuttle, T.; Murphy, J. A. J. Am. Chem. Soc. 2014, 136, 17818. doi: 10.1021/ja5101036

(31) Barham, J. P.; Coulthard, G.; Emery, K. J.; Doni, E.; Cumine, F.; Nocera, G.; John, M. P.; Berlouis, L. E. A.; McGuire, T.; Tuttle, T.; et al. J. Am. Chem. Soc. 2016, 138, 7402. doi: $10.1021 /$ jacs.6b03282 
(32) Gao, Y.; Tang, P.; Zhou, H.; Zhang, W.; Yang, H.; Yan, N.; Hu, G.; Mei, D.; Wang, J.; Ma, D. Angew. Chem. Int. Edit. 2016, 55, 3124. doi: 10.1002/anie. 201510081

(33) Paira, R.; Singh, B.; Hota, P. K.; Ahmed, J.; Sau, S. C.; Johnpeter, J. P.; Mandal, S. K. J. Org. Chem. 2016, 81, 2432. doi: $10.1021 /$ acs.joc.6b00002

(34) Zhang, L.; Yang, H.; Jiao, L. J. Am. Chem. Soc. 2016, 138, 7151. doi: $10.1021 /$ jacs.6b03442

(35) Yang, H.; Chu, D. -Z.; Jiao, L. Chem. Sci. 2018, 9, 1534. doi: $10.1039 / \mathrm{c} 7 \mathrm{sc} 04450 \mathrm{j}$

(36) Guo, Z. W.; Li, M.; Mou, X. Q.; He, G.; Xue, X. S.; Chen, G. Org. Lett. 2018, 20, 1684. doi: 10.1021/acs.orglett.8b00530

(37) Hou, L.; Zhou, Z.; Wang, D.; Zhang, Y.; Chen, X.; Zhou, L.; Hong, Y.; Liu, W.; Hou, Y.; Tong, X. Org. Lett. 2017, 19, 6328. doi: $10.1021 /$ acs.orglett.7b03135

(38) Studer, A.; Curran, D. P. Nat. Chem. 2014, 6, 765. doi: 10.1038/NCHEM.2031

(39) Hofmann, J.; Clark, T.; Heinrich, M. R. J. Org. Chem. 2016, 81, 9785. doi: $10.1021 /$ acs.joc.6b01840

(40) Roman, D. S.; Takahashi, Y.; Charette, A. B. Org. Lett. 2011, 13, 3242. doi: $10.1021 / 01201160$ s

(41) Sun, C. -L.; Gu, Y. -F.; Huang, W. -P.; Shi, Z. -J. Chem. Commun. 2011, 47, 9813. doi: 10.1039/c1cc13907j

(42) Bhakuni, B. S.; Kumar, A.; Balkrishna, S. J.; Sheikh, J. A.; Konar, S.; Kumar, S. Org. Lett. 2012, 14, 2838. doi: 10.1021/ol301077y

(43) Wu, Y.; Wong, S. M.; Mao, F.; Chan, T. L.; Kwong, F. Y. Org. Lett. 2012, 14, 5306. doi: 10.1021/ol302489n

(44) De, S.; Ghosh, S.; Bhunia, S.; Sheikh, J. A.; Bisai, A. Org. Lett. 2012, 14, 4466. doi: 10.1021/o13019677

(45) Simmons, E. M.; Hartwig, J. F. Angew. Chem. Int. Edit. 2012, 51, 3066. doi: 10.1002/anie.201107334 